\title{
Extracción de ADN de bacterias conservadas en el banco de cepas de la Universidad Francisco de Paula Santander sede Campos Elíseos
}

Extraction of DNA from bacteria preserved in the strain bank of the Universidad Francisco de Paula Santander head office Campos Elíseos

Liliana Yanet Suárez-Contreras, Luz Francy Yañez-Meneses ${ }^{\text {b }}$

${ }^{a}$ Magister en Biotecnología, lilianayanethsc@ufps.edu.co, orcid.org/0000-0001-8020-502X, Universidad Francisco de Paula Santander, Cúcuta, Colombia.

Ingeniero Biotecnológico, luzfrancyym@ufps.edu.co, orcid.org/0000-0003-4365-471X, Universidad Francisco de Paula Santander, Cúcuta, Colombia.

Cómo citar: L.Y. Suárez-Contreras y L.F. Yañez-Meneses, "Extracción de ADN de bacterias conservadas en el banco de cepas de la Universidad Francisco de Paula Santander sede Campos Elíseos”, Respuestas, vol. 23, no. S1, pp. 24 - 28, 2018. https://doi.org/10.22463/0122820X.1496

Recibido: Febrero 9, 2018; Aprobado: Julio 27, 2018

\begin{tabular}{ll}
\hline RESUMEN \\
\hline Palabras Clave: & $\begin{array}{l}\text { Actualmente, la identificación de bacterias se realiza con técnicas clásicas basadas en caracterización fenotípica a nivel } \\
\text { macroscópico y microscópico, sin embargo, este método no es fiable y no permite conocer la verdadera identidad del } \\
\text { Ácidos nucleicos }\end{array}$ \\
$\begin{array}{l}\text { Bacillus thurigiensis } \\
\text { E. coli }\end{array}$ & neguridad el género y especie. El objetivo de este trabajo fue estandarizar el método de extracción de ADN para bacterias Gram \\
Microorganismos & de una región específica de interés. Se evaluaron dos métodos de extracción, el protocolo de Wilson y el Kit de extracción \\
& Wizzard (Promega), los dos métodos se diferenciaron en la cuantificación por NanoDrop y se visualizaron por medio de una \\
electroforesis en gel de agarosa al 0,8\% utilizando el intercalante Gel red. Según el protocolo de Wilson solo se obtuvo ADN de & bacterias Gram negativas de buena calidad, y la relación 260/280 en el nanodrop (1,8-2). Mientras que el Kit de extracción \\
& Wizzard permitió obtener ADN para bacterias Gram positivas y negativas. Se obtuvieron mejores concentraciones de ADN con \\
el protocolo de Wilson, por otra parte no fue posible obtener ADN de bacterias Gram positivas siendo para este caso el kit & Wizzard un método sin limitaciones para extraer ADN de cualquier género de bacteria; a pesar de lo antes mencionado, por \\
costos es más conveniente el protocolo de Wilson, para extraer las bacterias Gram negativas.
\end{tabular}

\section{ABSTRACT}

\section{Keywords:}

Nucleic acids

Bacillus thurigiensis

E. coli

Microorganisms
Currently, the identification of bacteria is done with classical techniques based on the phenotypic characterization at macroscopic and microscopic level, however, this method is not reliable and does not allow knowing the true identity of the microorganism under study. For this reason it is necessary to carry out an identification at the molecular level that allows us to know with certainty the genus and species. The objective of this work was to standardize a method of DNA extraction for Gram-negative and Gram-positive bacteria according to the chemical characterization, which allowed obtaining good quality DNA for the amplification of a specific region of interest. Two extraction methods were evaluated, the Wilson protocol and the Wizzard extraction kit (Promega), the two methods were differentiated in the quantification by NanoDrop and visualized by means of a $0.8 \%$ agarose gel electrophoresis using the Intercalante Gel red. According to Wilson's protocol, only DNA from Gram negative bacteria of good quality was obtained, and the ratio 260/280 in the nanodrop (1.8-2). While the Wizzard Extraction Kit allowed to obtain DNA for Gram positive and negative bacteria. Better DNA concentrations were obtained with the Wilson protocol, and it was not possible to obtain DNA from Gram positive bacteria. For this case, the Wizzard kit was an unlimited method to extract DNA of any kind, according to the reasons mentioned above, the protocol that reduces costs in the laboratory and is the most convenient to extract the DNA from Gram negative bacteria is the one proposed by Wilson.

\section{Introducción}

El Banco de cepas de la Facultad de Ciencias Agrarias y del Ambiente, ubicado en el Centro Experimental Campos Eliseos de la UFPS, cuenta con una gran colección de microorganismos entre hongos y bacterias, producto de los diferentes proyectos de investigación realizados por estudiantes de los diferentes planes de estudio de la Facultad de Ciencias Agrarias y del Ambiente, especialmente del programa de ingeniería biotecnológica, estos microorganismos han sido identificados macroscópicamente y microscópicamente en su mayoría. Determinando algunas características de los géneros, pero no con certeza las especies.

En el año 2005, fue desarrollado por Suárez [1], un protocolo de extracción de ADN para hongos (M. roreri), que permitió realizar la identificación molecular de otros géneros de fitopatógenos con su respectiva especie. [2], [3]. Por lo tanto, para dar continuidad al trabajo que se viene realizando en el laboratorio de biotecnología molecular, y lograr identificar molecularmente dichos microorganismos; con el fin de explotar su potencial biotecnológico, especialmente en control biológico Suárez, 2006 [4], [5]. En este trabajo, se probó un nuevo protocolo para extracción de ADN de bacterias una de las técnicas útil para la identificación bacteriana, ha sido el manejo de pruebas bioquímicas, que se basan en la presencia o ausencia de una enzima, de un grupo de enzimas, o de una vía metabólica completa en uno o más microorganismos [6], pero estos métodos de evaluación presentan diferentes limitaciones, ya que no precisan con exactitud cuál es el organismo que se está

*Autor de Correspondencia. 
estudiando, tampoco son sensibles a las mutaciones genéticas (y conllevan a características diferentes), a las similitudes entre distintas especies o las disparidades entre cepas de una misma especie [7]. En la actualidad la identificación de los microorganismos se realiza por varios métodos, como fenotípicos, morfológicos, fisiológicos y moleculares, todo esto permite tener una identificación más precisa [7], [8].

La extracción del ADN es necesaria en multitud de aplicaciones de la biología molecular. Existe un gran número de kits comerciales. Se ha demostrado que la sensibilidad de detección de la PCR es diferente para diferentes kits de ADN [9].

El éxito de los métodos de extracción de $\mathrm{ADN}$, depende en gran medida de la eficacia de la extracción y de la calidad del ADN aislado [10], [11]. Además de la eficacia y eficiencia, los métodos de extracción adecuados también deben ser fáciles de manejar, ahorrar tiempo y ser asequibles. Preferiblemente, universales en su aplicación para reducir el número de procedimientos de extracción y posteriormente visualizarlo por medio de electroforesis y cuantificarlo por espectrofotometría. Sin embargo, se han desarrollado kits comerciales para la eficiente de extracción de ADN en diferentes tipos de muestras como: agua, suelo, cultivo líquido y sólido. Sin embargo, el uso de kits de extracción de $\mathrm{ADN}$ sigue siendo muy costosos durante el análisis de ADN, especialmente cuando se busca un alto rendimiento de la muestra o grandes cantidades. En este proyecto se estandarizó un método de extracción de ADN bacteriano que se comparó con el kit comercial Wizard (Promega). Se realizaron los ensayos tanto para bacterias del género Gram positivo como Gram negativo, ya que manejan pre-tratamientos distintos debido a la estructura de la pared celular de cada microorganismo.

\section{Materiales y métodos}

Se utilizaron dos microorganismos de referencia que fueron: $E$. coli (Gram negativo) y Bacillus thurigiensis (Gram positivo). Que fueron previamente reactivados en medios líquidos selectivos y luego se ensayaron dos métodos de extracción de ADN: protocolo de Wilson y el kit de extracción Wizard (Promega) [12].

El protocolo de Wilson [13], consistió en tomar 1,5 ml de cultivo líquido de cada bacteria a un microtubo de $1.5 \mathrm{ml}$, luego se centrifugó a $13000 \mathrm{rpm} / 5 \mathrm{~min}$, luego se descartó el sobrenadante y se resuspendió el pellet en $550 \mathrm{ml}$ de buffer TE. Posteriormente para Bacillus thurigiensis se adicionó $10 \mu \mathrm{l}$ de lisozima $(10 \mathrm{mg} / \mathrm{ml})$ y se incubó $1 \mathrm{~h} / 37^{\circ} \mathrm{C}$; en el caso de E. coli directamente se le agregaron $8 \mu \mathrm{l}$ de proteinasa $\mathrm{k}$ y $30 \mu \mathrm{l}$ de SDS $10 \%$ y se incubó a $1 \mathrm{~h} / 37^{\circ} \mathrm{C}$. Para Bacillus thurigiensis luego de la incubación se adicionaron $8 \mu$ lde proteinasa k y 30 $\mu 1$ de SDS $10 \%$ y se incubó $1 \mathrm{~h} / 37^{\circ} \mathrm{C}$. Luego del pretratamiento para ambos microorganismos, se continuo el procedimiento agregando $100 \mu \mathrm{l}$ de $5 \mathrm{M}$ de $\mathrm{NaCl}$ y $80 \mu \mathrm{l}$ de $\mathrm{CTAB} / \mathrm{NaCl}$ se mezcló con micropipeta y se incubó a $65^{\circ} \mathrm{C} / 10 \mathrm{~min}$; posteriormente se agregó $750 \mu 1$ de Cloroformo/alcohol-isoamílico y se centrifugó a $13000 \mathrm{rpm}$ durante $10 \mathrm{~min}$ para luego nuevamente rescatar el sobrenadante y repetir el paso con fenol/cloroformo/alcohol-isoamilico y luego se centrifugó, se recuperó el sobrenadante y se precipitó el ADN con isopropanol para luego realizar un lavado con etanol al 70\% y finalmente se rehidrató el ADN aislado con buffer TE y se conservó a $2{ }^{\circ} \mathrm{C}$.

El procedimiento de kit Wizard (Promega) [12], consistió en tomar $1,5 \mathrm{ml}$ de caldo de cultivo de cada bacteria y se centrifugó a $13000 \mathrm{rpm} / 3 \mathrm{~min}$ y luego se descartó el sobrenadante y el pellet para el caso de Bacillus thurigiensis se resuspendió en $480 \mu \mathrm{l}$ de EDTA y se le adicionó $120 \mu \mathrm{l}$ de lisozima y se incubó $45 \mathrm{~min} / 37^{\circ} \mathrm{C}$, después de dicho tiempo se centrifugó y el pellet se resuspendió en $600 \mu \mathrm{l}$ de Nuclei Lysis Solution, en este paso comienza la metodología para E. coli. Se incubó a $80^{\circ} \mathrm{C} / 5 \mathrm{~min}$, se dejó enfriar y se le adicionaron $3 \mu \mathrm{l}$ de RNA solution, se mezcló por inversión y se incubó a $37^{\circ} \mathrm{C} / 45 \mathrm{~min}$ para posteriormente adicionar $200 \mu \mathrm{l}$ de Protein Precipitation, después se incubó en hielo por $5 \mathrm{~min}$, se centrifugó y se recuperó el sobrenadante y se precipitó el ADN con isopropanol, se centrifugó y lavó el ADN con etanol al 70\%. Finalmente se rehidrató el ADN con DNA Rehydratation Solution a $65^{\circ} \mathrm{C} / 1 \mathrm{~h}$ y luego se llevó a conservar a $2^{\circ} \mathrm{C}$.

La visualización del ADN obtenido se realizó mediante la electroforesis en un gel de agarosa al $0,8 \% \mathrm{p} / \mathrm{v}$, utilizando el agente intercalante Gel Red y a un voltaje de $120 \mathrm{~V} / 2 \mathrm{~min}$ y $100 \mathrm{~V}$ por $50 \mathrm{~min}$. Después, la cuantificación se realizó mediante espectrofotometría utilizando el NanoDrop. Se consideró la proporción de la absorbancia a 260/280 nm para estimar la pureza del $\mathrm{ADN}$. Las muestras se consideraron respecto a valores $\geq 1.8$, ya que estos valores son aceptados como ADN Puro y valores menores a este indican la presencia de proteínas. También se tuvo en cuenta una segunda valoración de la pureza mediante la proporción 260/230 nm, y los valores aceptados estuvieron en el rango de 2.0-2.2, ya que si la relación es menor indica la presencian de contaminantes como carbohidratos o fenol [14].

\section{Resultados y análisis}

Según el protocolo de Wilson solo se obtuvo ADN de bacterias Gram negativas de buena calidad, y la relación 260/280 en el nanodrop (1,8-2). Mientras que el Kit de extracción Wizzard permitió obtener ADN para bacterias Gram positivas y negativas. 


\begin{tabular}{|c|c|c|c|}
\hline Bacteria & $\mathbf{n g} / \mathbf{\mu l}$ & $\mathbf{2 6 0 / 2 8 0}$ & $\mathbf{2 6 0 / 2 3 0}$ \\
\hline E. coli & 168,6 & 1,47 & 0,76 \\
\hline E. coli & 280,9 & 1,62 & 0,97 \\
\hline $\begin{array}{c}\text { Bacillus } \\
\text { thurigiensis }\end{array}$ & 104,2 & 1,56 & 0,79 \\
\hline $\begin{array}{c}\text { Bacillus } \\
\text { thurigiensis }\end{array}$ & 37,3 & 1,88 & 2,28 \\
\hline
\end{tabular}

Tabla II. Cuantificación de ADN aislado usando el Kit Wizard

\begin{tabular}{|c|c|c|c|}
\hline Bacteria & $\mathbf{n g} / \mathbf{\mu l}$ & $\mathbf{2 6 0 / 2 8 0}$ & $\mathbf{2 6 0 / 2 3 0}$ \\
\hline E. coli & 78,4 & 1,92 & 1,45 \\
\hline E. coli & 132,7 & 1,94 & 1,35 \\
\hline E. coli & 221,1 & 1,9 & 1,71 \\
\hline $\begin{array}{c}\text { Bacillus } \\
\text { thurigiensis }\end{array}$ & 22,4 & 1,28 & 0,28 \\
\hline $\begin{array}{c}\text { Bacillus } \\
\text { thurigiensis }\end{array}$ & 23,5 & 1,48 & 0,53 \\
\hline $\begin{array}{c}\text { Bacillus } \\
\text { thurigiensis }\end{array}$ & 47,9 & 1,53 & 0,43 \\
\hline
\end{tabular}

El protocolo de Wilson permitió obtener ADN de mejor calidad sin embargo no fue posible obtener ADN de bacterias Gram positivas (Figura 1) siendo para este caso el kit Wizzard un método que no delimita el género bacteriano para extraer ADN (Figura 2)

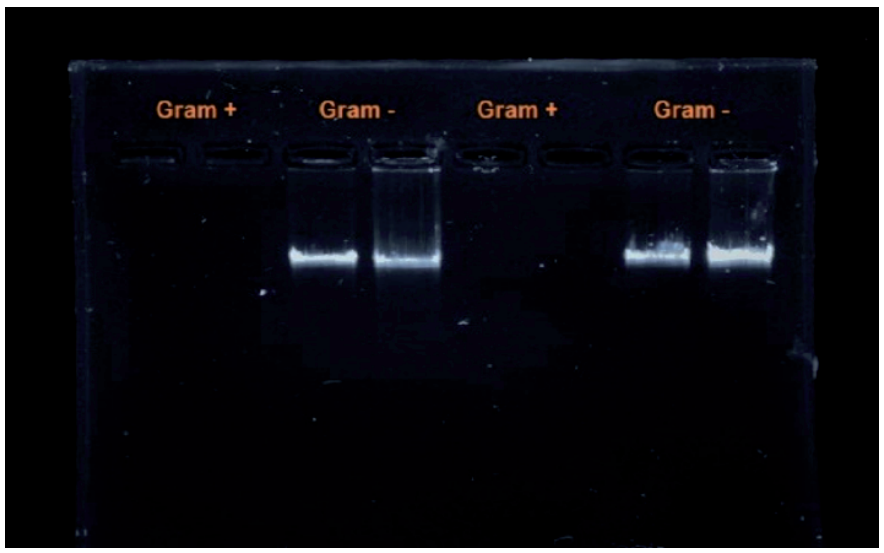

Figura 1. Gel de agarosa $0,8 \% \mathrm{p} / \mathrm{v}$. Muestras de ADN aisladas de bacterias Gram + y -, utilizando el protocolo de Wilson

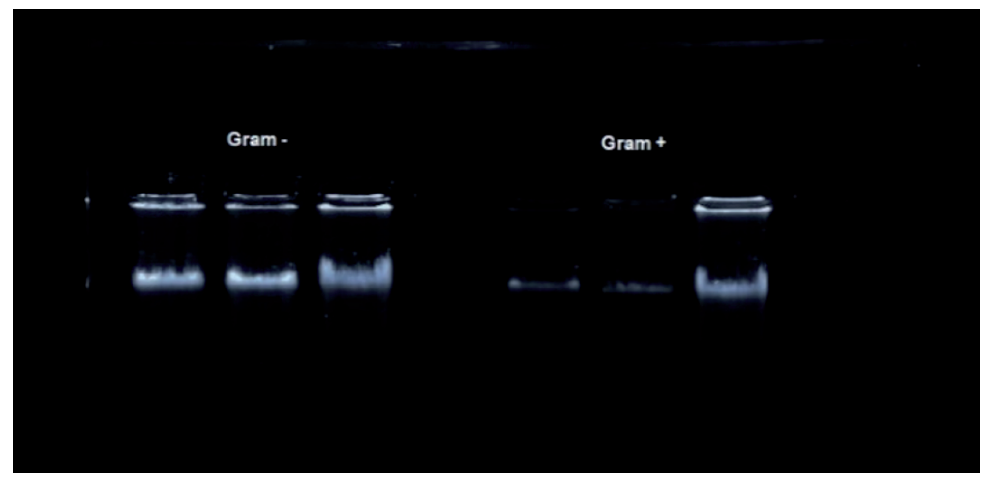

Figura 2. Gel de agarosa $0,8 \%$ p/v. Muestras de ADN aisladas empleando el Kit Wizard de Promega

\section{Discusiones}

La cantidad del ADN extraído y purificado fue suficiente para las subsiguientes aplicaciones. La correcta eliminación de contaminantes proporcionó ADN de gran calidad y pureza [15], [16], suficiente para dar continuidad a otros protocolos de biología molecular, como PCR.

La absorción de luz ultravioleta fue utilizada para evaluar la pureza del ADN extraído. Para una muestra pura de $\mathrm{ADN}$, la relación entre la absorbancia a 260 y $280 \mathrm{~nm}$ (A260/A280) es 1.8. Una relación < 1.8 indicó que la muestra se encuentra contaminada con proteínas o solventes orgánicos como fenol, [17].

De acuerdo con McIlroy et al. [18], la integridad del ADN también es un factor crucial para otras técnicas moleculares, ya que las regiones de genes grandes pueden no ser amplificables debido a los daños estructurales. Para verificar la integridad del ADN solo con base a la visualización del ADN en gel de agarosa puede ser poco confiable. Es por esta razón que se verificó la calidad del ADN mediante espectrofotometría utilizando el NanoDrop.

La efectividad de tener un buen método de extracción da lugar para estudiar diferentes regiones de interés, en el caso de las bacterias, una eficiente extracción de $\mathrm{ADN}$ permite amplificar la región $16 \mathrm{~s}$, sitio que revela la verdadera identidad a la pertenece la bacteria [19], [20]. 


\section{Conclusiones y recomendaciones}

Se concluye que por reducción de costos es más factible utilizar el protocolo de Wilson para la extracción de ADN de bacterias Gram negativas, sin embargo, para las bacterias Gram positivas solo es posible la obtención del ADN utilizando el kit comercial en este caso el Wizzard.

Este trabajo contribuye a dar continuidad a otros proyectos para poder realizar caracterización a nivel molecular de bacterias sin distinción de género que permitirá conocer la verdadera identidad de las bacterias y encaminar sus aplicaciones en diferentes intereses investigativos

\section{Referencias}

[1] L. Suárez, "Extracción y purificación del ADN de Moniliophthora roreri hongo que ataca el cacao, en norte de santander", Respuestas, vol. 10, no. 2, pp. 4-8, 2005.

[2] Espitia, A. Identificación molecular mediante ITS de los fitopatógenos Fusarium sp., Alternaria sp., Rhizopus sp., Aspergillus sp., Curvularia sp., pertenecientes al banco de cepas de la Universidad Francisco De Paula Santander, Sede Campos Elíseos. Trabajo de grado. 2018

[3] Suárez, L. y Peñaranda, F. Identificación molecular de los aislamientos de hongos biocontroladores conservados en el banco de cepas de la Facultad de Ciencias Agrarias y del Ambiente de la Universidad Francisco de Paula Santander. Proyecto FINU 042-2016. 2018

[4] L. Suárez, "Aislamiento e identificación de Moniliophthora roreri causante de la moniliasis en municipios del nororiente Colombiano", Respuestas, vol. 11, no. 1, pp. 3-8, 2006.

[5] L. Suárez y C. Cabrales, "Identificación de especies nativas de Trichoderma sp, y Bacillus. Evaluación de su potencial antagonista in vitro frente al hongo fitopatógeno nativo Moniliophthora roreri en el departamento de Norte de Santander", Respuestas, vol. 13, no. 1, pp. 45-56, 2008.

[6] Bou, G., Fernández, A., Garcia, c., Sáenz, J., \& Valdezcate, S. Métodos de identificación bacteriana en el laboratorio de microbilogía. Enfermedades infecciosas y microbiología clínica, 601-608. 2011. doi:10.1016/j.eimc.2011.03.012

[7] Godoy, M., Orozco, L., Hernández, C., DaMatac, O., De Waard, J., \& González, S. Identificación de micobacterias no tuberculosas: comparación de métodos bioquímicos y moleculares. Revista de la Sociedad Venezolana de Microbiología, 96-104. 2008.

[8] Rubio, E. Caracterización molecular y funcional de bacterias del género Azotobacter aisladas de suelos de la República Argentina. El rol de las auxinas en la respuesta a la inoculación de trigo. Buenos Aires: Tesis de Maestría. 2003

[9]Yoshikawa H, Dogruman-Al F, Dogruman-Ai F, Turk S, Kustimur S, Balaban N, et al. Evaluation of DNA extraction kits for molecular diagnosis of human Blastocystis subtypes from fecal samples. Parasitol Res;109:1045-50. 2011

[10] Singka, D., Kumdhitiahutsawakul, L., Rekkriangkrai, P., Pathom-aree, W. A simple method for DNA extraction from activated sludge. Chiang Mai J. Sci. 39, 111-118. 2012

[11] Gabor, M.E., de Vries, E.J., Janssen, D.B. Efficient recovery of environmental DNA for expression cloning by indirect extraction methods. FEMS Microbiol. Ecol. 44, 153-163. 2003

[12] Ramachandran V, Ismail P, Stanslas J, Shamsudin N. Analysis of renin-angiotensin aldosterone system gene polymorphisms in Malaysian essential hypertensive and type 2 diabetic subjects. Cardiovasc Diabetol. 8:11 p 2009

[13] Wilson, K. Preparation of genomic DNA from bacteria, in Current Protocols in Molecular Biology (Ausubel, F.M., Brent, R.,Kingston, R.E., Moore, 
D.D., Seidman, J.G., Smith, J.A., et al.), Wiley, New York, pp. 241.-245. 1987

[14] Alejo, L., Aragón, M., \& Cornejo, A. Extracción y purificación de ADN. Herramientas moleculares aplicadas en ecología. 1-26 p. 2008

[15] Coolen M. 7000 years of Emiliania huxleyi viruses in the Black Sea. Science. 333:451-2. 2011

[16] Yuan S, Cohen D, Ravel J, Abdo Z, Forney L. Evaluation of methods for the extraction and purification of DNA from the human microbiome. PLoS ONE.7: e33865. 2012

[17] Claassen S, du Toit E, Kaba M, Moodley C, Zar $\mathrm{H}$, Nicol M. A comparison of the efficiency of five different commercial DNA extraction kits for extraction of DNA from faecal samples. J Microbiol Methods. 94:103-10. 2013

[18] McIlroy, S.J., Porter, K., Seviour, Tillett, D. Extraction nucleic acid from activated sludge which reflect community population diversity. A. Van Leeuw. 96, 593-605. 2009. http://dx.doi.org/10.1007/s10482-009-9374-z.

[19] Meyer RL, Saunders AM, Blackall LL. Putative gly-cogen-accumulating organisms belonging tothe Alpha-Proteobacteria identified through rRNA-based stable isotope probing. Microbiology 152:419-429. 2006

[20] Ahn J, Schroeder S, Beer M, McIlroy S, Bayly RC, May JW,Vasiliadis G, Seviour R.J. Ecology of the microbial community removing phosphate from wastewater under continuously aerobic conditions in a sequencing batch reactor. Appl Environ Microbiol 73:2257-2270. 2007 